\title{
The Use Of A Service-Learning Model And Online Dialogue To Promote Reflection, Critical Thinking, And Cultural Competence In Early Childhood Studies Students \\ Kim E. Riordan, (Email: kriordan@umn.edu), University of Minnesota
}

\begin{abstract}
Service learning has grown in popularity as an effective model to enhance critical reflection. A characteristic of effective service learning is the linking of "hands on" experience in the community with academic curriculum. A service learning initiative between a 4-year college early childhood teacher preparation program and an Early Head Start (birth - age 3) program located on an American Indian reservation is effectively combined with asynchronous online dialogue. The results suggest an increase in self-awareness and cultural competence. This paper explores service learning, the use of online dialogue to promote self-awareness and reflection, and the convergence of these two teaching strategies to enhance cultural competence in a multicultural world.
\end{abstract}

\section{INTRODUCTION}

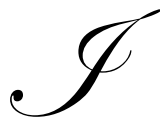

$\mathrm{t}$ is generally believed that service learning as a teaching model is an effective tool to aid student's understanding of the communities within which they work and the roles they can play in service to others. A key component of service learning is the linkage between hands-on work in the community and academic curriculum (Anderson, 1998; Furco, 1996). Service learning experiences provide the source for student reflection.

The use of online, asynchronous dialogue is growing in popularity as an effective tool to enhance reflection in the classroom (Winiecki, 2003; Granger \& Bowman, 2003). Asynchronous dialogue (online discussion independent of place and time) can be viewed as a classroom equalizer. It affords students who are not as likely to participate in a face-to-face class discussion an opportunity to engage in dialogue in a less threatening, non-competitive arena (Horton, 2001). Everyone's voice gets heard in an asynchronous dialogue. Indeed, online discussion can facilitate productive, reflective discourse (Kirk \& Orr, 2003). Online asynchronous dialogue becomes the vehicle for student reflection.

Our ability as teacher educators to enhance the cultural competence of our students has become a social imperative (Teidt \& Teidt, 1999; Wolfe \& Falk-Ross, 2002; and Derman-Sparks \& Brunson Phillips, 1997). Students entering the teaching field must be prepared to work in a multicultural world. Most importantly, educators must be able to question their own assumptions, be able to reflect on their own practice, and be aware of the privilege with which most of them earned their degrees (Howard, 1999; Paley, 2000; and Sleeter, 2002). The ability to critically reflect on one's assumptions and experiences enhances cultural competence.

These three elements: service learning, online asynchronous dialogue, and the ability to critically reflect converge to enhance student's cultural competence. This paper provides an overview and rationale for the use of a service-learning model coupled with online asynchronous dialogue to promote self-awareness and critical reflection in 
a teacher preparation program. Further, this paper describes the use of this combination of modalities in an early childhood teacher preparation program. Recommendations for implementation are offered.

\section{SERVICE LEARNING}

Service learning can be viewed as both an instructional method and a philosophy of education (Anderson, 1998). In terms of philosophy, service learning makes operational the belief that education should foster social responsibility; students should see themselves as social change agents in a democratic world. As an instructional method, service learning combines service in the community with academic studies. Service learning, however, is not the same as community service. Service learning clearly differentiates itself from other experiential learning and education in terms of who directly benefits from the service experience. While community service generally involves students providing service(s) to an individual or group of individuals (wherein the primary beneficiary is the service recipient), the focus of service learning should benefit both parties; the recipient of the service and the provider of the service (Furco, 1996). The Corporation for National and Service Learning (2005) describes service learning as:

- A method whereby students learn and develop through active participation in thoughtfully organized service that is conducted in and meets the needs of communities

- Is coordinated with an elementary school, secondary school, institution of higher education, or community service program and the community

- $\quad$ Helps foster civic responsibility

- Is integrated into and enhances the academic curriculum of the students, or the education components of the community service program in which the participants are enrolled

- $\quad$ And provides structured time for students or participants to reflect on the service experience. (Corporation for National and Service learning)

Among the many reasons for integrating service learning into college coursework, there are several that standout: (1) to prepare new teachers to use service learning with their own students; (2) to help socialize teachers in the essential moral and civic obligations of teaching, including adapting to the needs of learners with diverse and special needs and having a commitment to advocate for social justice for children and families; and (3) enhancement of pre-service teachers' ability to reflect critically on current educational practices and their own teaching (Anderson, 1998, p. 3).

Service learning is not without its cautions. It appears that, unless well guided, the experience can promote a deficit notion of families who are economically poor, as well as reinforcing stereotypes of people of color (Grady, 1997). It is critical student's experiences out in the field are combined with discussions about the differences between what they are learning in the academic classroom and what they perceive is occurring in the service learning classroom. Oftentimes, there is discontinuity between the two. It is crucial classroom discussion is well facilitated in order for students to understand the inherent and systemic issues that evolve from inequities in power and privilege.

\section{CULTURAL COMPETENCE IN A MULTICULTURAL WORLD}

It is widely suggested that diversity in American classrooms may well be the most significant issue facing teachers in the new millennium (Delpit, 1995; Grady, 1997). An important question to explore with students is this: What does it mean in the life of students of color (or students who are economically poor or differently-abled) to have a teacher who is likely white, and inherently privileged? It is critical that "pre-service teachers who are members of the dominant group might come to examine their own assumptions about the deficiencies of others, about who deserves an education, and about the exclusionary practices of the institution of schooling" (Grady, p. 5).

Tiedt and Tiedt (1999) define multicultural education as "an inclusive teaching/learning process that engages all students in (1) developing a strong sense of self-esteem, (2) discovering empathy for persons of diverse cultural backgrounds, and (3) experiencing equitable opportunities to achieve to their fullest potentials" (p. 18). One more definition of multicultural education suggests it is "comprehensive and fundamental to all educational 
endeavors...advocates of education that is multicultural are consistent in their belief that respect for diversity and individual difference is the concepts' central ingredient" (Dodd, 1987).

Pre-service teacher's perceptions of the children and families they will work with must be explored in order to uncover prejudice and stereotyping. It appears teachers treat children differently based upon their expectations, and in turn, children respond to the teacher's treatment in ways that consistently confirm the expectations. This is supported by Jussim's (1986) integrated theory of self-fulfilling prophecies. It is critical we prepare pre-service teachers to have the expectation that all children are capable of learning, regardless of ethnicity, gender, age or socioeconomic factors (Pettit \& Sugawara, 2001).

Banks' (1988) framework of multicultural education proposes that personal transformation on the part of the teacher is what is necessary to create change in school, and ultimately in the world. Wolfe and Falk-Ross (2002) state, "Field experiences in diverse settings can optimally serve to heighten pre-service teachers' awareness of cultural, linguistic, and learning differences among young children, and become the stimulus for open and difficult discussion that leads to new learning and reflective practice" (p. 158).

\section{ONLINE ASYNCHRONOUS DISCUSSION}

"Research evidence strongly suggests that threaded discussion forums are excellent tools to engage online students in dialogue" (Kirk \& Orr, p. 4). The ability for students to think about what is happening, having time to reflect before they answer discussion questions, appears to make a dramatic difference in how students who would not otherwise participate, are able to engage in discourse with classmates.

Horton (2001) believes that face to face or real time class discussions are not as productive for student learning, primarily because it does not allow students an opportunity for deeper thinking, and reflective responses. Here's how this works. The instructor/facilitator decides on questions that are relevant to both the academic curriculum and the student's experiences in the field (at the service learning site). Students discuss within small, online groups the discussion question(s), creating both content knowledge and transformative learning. For example, through reading what others are experiencing, a student's perspective may be broadened, thereby creating a perspective transformation. Mezirow (1991) contends a unique property of adulthood is the ability to be able to critically reflect upon one's assumptions and that, by virtue of that activity, one's perspective is broadened. The student may realize they were not looking at the whole picture, or that perhaps they had some preconceived notions about a particular family, which turned out to be false. Through this process of questions, re-examining, and formulating new views of the world, the student is becoming a critically reflective teacher (Brookfield, 1995).

An essential component to the success of online course delivery, including asynchronous dialogue, is the proper facilitation of online discussion. Instructors must learn how to ask meaningful questions in order to both promote knowledge construction and engender reflection (Knowlton, 2001). It is this facilitation skill set that appears to predominantly make the difference between a mediocre online experience and one in which the results of student's discussions transcend both the coursework and the service learning experience. New meaning and awareness results from the synthesis of the two. "Online learning must be utilized correctly in order for it to be successful" (Arant, Colemand \& Daniel, 2002, p. 7).

\section{REFLECTION AND CRITICAL THINKING}

Changing the way pre-service teachers think about the world requires teacher educators to provide students with opportunities to examine and question their attitudes and beliefs about working with diverse populations. Giving students rich and ample experiences to be in settings that are diverse allows students to deepen their understanding of the students they are (and will be) working with (Zeichner, 1992). Without the experiences upon which to draw, student's reflections are based on superficial understandings of people, cultures and the role of education; often based on stereotypical notions of groups within the larger society. This can lead to reinforcement of stereotypes and disallows critical thinking of their role as teacher in the lives of diverse student populations. "Ultimately, it is this 
direct exposure to children from a variety of cultural, socio-economic, and family backgrounds that leads to enhanced sensitivity and effectiveness on the part of teachers" (Wolfe \& Falk-Ross, 2002, p. 157).

Critical thinking requires we engage in an internal dialogue with ourselves. This is more challenging if the students we are encouraging to do this have limited information upon which to draw from. Depending on the breadth of experience among the students, and the learning that has already occurred in previous classes, critical thinking will require the teacher educator to guide the students through the process of critical thinking in a way that will ideally become quite natural to them over time. There are a number of well-researched findings that can improve students' thinking skills (Heiman \& Slomianko, 1986). These are: (1) Help students remember what they have read, (2) Help students improve problem solving skills, and (3) Help students become aware of both their own and other's learning styles and how that impacts learning and teaching. These and other strategies are useful in helping students to think about their thinking.

\section{INTEGRATION OF SERVICE LEARNING AND ASYNCHRONOUS DIALOGUE}

Service learning and asynchronous dialogue was incorporated into 3 of the 4 courses that students in an early childhood studies program enrolled in for their first block of early childhood specific coursework. One of the requirements for the courses was participation in a seven and a half hour per week practicum/service learning placement. All of the placements were in infant or toddler classrooms within the community, most of which were at an Early Head Start program located on an American Indian Reservation. Because of the limited number of classrooms and days, which students could participate in the Early Head Start program, students were also placed in private and public infant/toddler childcare facilities during the semester. Throughout the semester students were expected to participate in the early childhood settings as though they were entry-level assistants, providing support and assistance to the classroom teachers, all of whom had agreed to have students in their classrooms. In addition, students were expected to conduct a number of informal observations, interviews, and assessments of the classroom and the children. Students were unable to pass their courses until they had successfully participated at their service-learning site.

A primary goal of the academic program's decision to approach the Early Head Start program was two-fold. The first goal was to provide support to early childhood programs in the form of student assistance. The state mandated ratio of at least 1 adult per 7 toddlers and 1 adult per 4 infants did not provide adequate opportunities for 1:1 care of young children. Having students who were able to interact with young children, supporting activities throughout the day, and assisting teachers in preparing the classroom, was reported to help immeasurably at service learning sites. The second goal was to provide students with a culturally diverse placement in which to begin to explore some of the assumptions, values and beliefs they held about people of different cultures than their own. Through a series of meetings between university faculty and Head Start staff, agreement was reached on a variety of issues, including expectations for students by the cooperating teacher, anticipated schedules for observing students in the field, and possibilities for mutual training opportunities.

The use of online asynchronous dialogue was seen as a viable option for a portion of the classroom discussions, particularly as it related to processing what students were reading in their textbooks, and for discussion of multicultural and diversity related topics. Given the research on asynchronous dialogue, and the experiences of several of the instructors within the program, it was deemed appropriate for this undergraduate teacher preparation program. Depending on the course, students were required to either participate in asynchronous discussion on a weekly basis (in lieu of one hour of class time per week) or on an every other week basis (in lieu of face-to-face class on alternating weeks). Students had a variety of questions to explore, often relating to what they were experiencing at their servicelearning site. Following are samples of discussion and reflection that was occurring in the online asynchronous dialogue during one semester of service learning.

\section{Online Reflection Question, As It Related To The Practicum Site And Textbook}

Do you think that you and the people you're working with at your practicum sites share the same philosophy about young children? Why or why not? 
I have learned over the past 8 weeks of school that I am getting closer to being a teacher everyday, and that it is really cool but also kind of scary... the practicum is more professional compared to the other practicum sites we have worked on in the past. These practicums allow us to actually teach the children lessons that we didn't get to teach at our other practicums. I still have frustrations about some of the people at my practicum and the things that they do, but I'm getting through!

Some of the triumphs are that the children have seemed to develop a friendship with me and this is cool to see because I only go there once a week. It is neat to see the trust issues and all the bonding develop over the course of the semester.

Something that I didn't know about myself is my inability to speak up at times.... I have always thought of myself as assertive and communicative about things that I think are wrong but this situation seems different. It is probably because it is not entirely my place to tell the teachers what to do, or my lack of confidence in knowing exactly what to do to change it or the right way to say it. I have gotten more confident though and have begun to take initiative such as reading stories and doing activities with the toddlers

\section{Online Reflection Question, As It Related To Personal Growth And Critical Thinking}

What are you learning about yourself, as a result of the past 8 weeks of classes and practicum?

I'm learning that it is ok to have your way of doing things and that everyone is different. I'm building a base of my preferences and interests and building off of them.

I think that what I am learning is that everyone has their own beliefs and own ways of doing things. We each bring our own experiences and have our own thoughts on how we think children learn and develop. This is something that I am noticing with the teachers I am working with. They have their own methods, which are okay, but I might have a different approach that I would take with the children. I guess what I am learning is that it is okay to do things your own way. It may sound strange, but I thought that the best way to teach is by example. Many times it will be from your own beliefs and experiences.

Okay, honestly, I feel like every week I go to this classroom, I realize that I know less than I thought I did. The challenging behavior in the class is a constant reminder that you can never really know everything there is to know about preventing and dealing with challenging behavior.

It's funny, because in those moments when I'm quickly thinking of what to do or say (it's usually a second or two), I am not scrolling through the pages of the book we are reading. I am acting on my instinct. I think that reading the book has helped me incorporate new ideas into my instincts, but I don't think through all the suggestions on those pages in those two seconds. I'm not sure what that means exactly, it's just what I've noticed.

During these past eight weeks I think I've learned a lot about myself. The biggest thing I've learned to take a closer look at how I interact with children. I've learned to step away more and just watch and observe the children, what they are doing and what they are learning, instead of always trying to interact with them, talk with them, ...etc.

\section{Online Reflection Question, As It Related To State Board Of Teaching Standards And Cultural Competence}

The teacher understands how students differ in their approaches to learning and creates instructional opportunities that are adapted to learners from diverse cultural backgrounds and with exceptionalities.

Last week, during the free play time, there was one boy who was running around with feathers and a headpiece on, making a lot of noise like he was at a pow wow. I was sort of watching him out of the corner of my eye, but was really talking to kids while they were playing with play dough. When it was time to clean up, he was just running all around the floor, making a bunch of noise (which was interesting, he's one of the quiet ones), and finally 
the teacher told him it was time to put the head piece away and come to the circle. So he did. Then she turned to me and smiled and said, "Wow. He was really into that. But it's okay, he's native." And I thought about that for a while when I left. And I realized what the teacher was saying...it's his culture.... and he's dancing and singing because that is a form of expression for him. Had it been another child and there was an air of making fun of that, the teacher would have stopped it. To recognize what is done as a way of life and what is done because it's funny was a good lesson to learn last week.

I was trying to think about how my cooperating teachers help to nurture these things in the classroom. Sometimes the teachers will realize that a particular child is really interested in a particular activity, so they may include additional toys, or activities that would help foster that interest.

The teacher understands and uses a variety of instructional strategies to encourage student's development of critical thinking, problem solving, and performance skills. The teacher must demonstrate flexibility and reciprocity in the teaching process as necessary for adapting instruction to student responses, ideas and needs.

One day we did this art project where the children were given paper plates and the teacher squirted yellow paint on the plate and demonstrated and helped the children to spread the paint on the plate. Every child reacted completely differently; one needed more guidance, while one picked up on it right away. But the oldest child, easily and quickly covered her moon, and used all of her paint, and she requested more paint. She wanted to continue working...So I think this is an example where a teacher can be flexible in knowing when to provide further stimulation and opportunities for the child to continue based on the age and development level.

I think that this means teachers need to approach the learning process from a variety of ways. Art, music, free-time, outside time. I have seen my teachers do a pretty good job of this. Although they are only babies they keep their environment changing so that they are learning and experiencing new things all the time

\section{CONCLUSION}

The service learning experience supported the goals and learning objectives of the courses students were enrolled in. This was evidenced by the ability to reflect on their learning at a deep, meaningful level. Students described learning more than they could have imagined. Significantly, student's perspectives about themselves, and the people they worked with, changed in measurable ways. Along with the hands-on experience at the service learning site, and the opportunity to reflect in online discussions, students came to understand their role as teacher in the lives of the children they worked with from a different perspective. Overall, it seemed that the pre-service students appeared to take themselves, and their role, more seriously.

There are a number of caveats that may be helpful as guides in planning a mixed modality such as this - the use of asynchronous dialogue and service learning to enhance critical reflection and cultural competence:

- $\quad$ Establish and maintain ongoing professional relationships with staff at the service learning site(s). Strong relationships form the foundation of the success of service learning initiatives.

- $\quad$ Require students to participate in the online discussion forum (points or attendance should be attached)

- Help students to know how to use the online format. Discuss issues such as expectations, netiquette, and evaluation. There should be clearly communicated expectations for posting and responding within the online format.

- Create a user-friendly structure for discussions, regardless of the format used (Blackboard, WebCrossing, WebCT, etc.). Links to the course syllabi and to the instructor(s) are important. Do not let technology get in the way of the learning objective, which is to have productive, reflective online discussion. Tech support is crucial.

- $\quad$ Create discussion questions that are not only relevant to students but require them to think about issues on a deeper level, i.e. avoid knowledge and comprehension questions, and ask questions that are geared more for analysis and synthesis (referring to Bloom's taxonomy).

- Require students to have more than casual-friendly discussions with one another. Expectations should be clear, such as: Students will respond to the discussion question, as well as read and respond to group 
members' posts, by the end of the first week of the unit. Establish time limits regarding when students should post their initial responses, as well as responses to one another. It is helpful if students can participate in some of this planning.

- Community building exercises within the discussion groups will enhance student's comfort level with problem solving, and sharing more personal feelings, attitudes and beliefs. This is especially true if most of the students do not know each other well.

- Collaboration among instructors teaching the same group of students is important, in order to avoid duplication of discussion questions.

"Within a constitutional democracy, the central mission of the public schools is to prepare students for democratic citizenship. This mission requires the development of candidates who embrace and teach democratic values, including tolerance, commitment to human rights, and a commitment to work together for the common good" (American Association of Colleges for Teacher Education, 2002, p. 5). The challenge, it would seem, is it to help preservice teachers understand the importance of their role, and to further understand the impact they will have on their students if they are dysconscious of issues around privilege, disenfranchisement and empowerment (Howard, 1999). Boyle-Baise (1998) suggests that the task of helping pre-service teachers to think critically about this role is a formidable task. "A radical democratic approach to community service-learning can inform white pre-service teachers about empowerment and bolster teachers-to-be who are budding activists" (p. 13). It just may be these budding activists who will change the world.

\section{REFERENCES}

1. American Association of Colleges for Teacher Education. (2002). Meeting NCATE Standards through service-learning: Disposition. (Professional Issues Brief). NY: AACTE Publications.

2. Anderson, J. (1998). Service learning and Teacher Education. ERIC Digest. ED 421481. ERIC Clearinghouse on Teaching and Teacher Education, Washington DC.

3. Arant, M., Coleman, A., \& Daniel, B. (2002). Instructional strategies for on-line courses in education. ED 471350.

4. Banks, J. (1988). Multiethnic Education: Theory and Practice. Boston: Allyn \& Bacon.

5. Boyle-Baise, M. (1998). As good as it gets? The impact of philosophical orientations on community-based service learning for multicultural education. ED 429922.

6. $\quad$ Brookfield, S. (1995). Becoming a Critically Reflective Teacher. San Francisco: Jossey-Bass.

7. Corporation for National Community Service. (n.d.). Retrieved 1/17/05 from http://www.nationalservice.org/

8. Delpit, L. (1996). Other people's children: Cultural conflict in the classroom. New York: The New Press.

9. Derman-Sparks, L. \& Phillips, C. (1997). Teaching/learning anti-racism: A developmental approach. NY.

Teachers College Press.

10. Dodd, C. (1987). Dynamics of intercultural communication. Dubuque, Iowa: Brown.

11. Furco, A. (1996). Service-learning: A balanced approach to experiential education. Expanding Boundaries: Serving and Learning, 1(1), 2-6.

12. Grady, K. (1997). Constructing the other through community service learning. ED 431698 Retrieved 1/05.

13. Granger, D. \& Bowman, M. (2003). Constructing knowledge at a distance: The learner in context. Handbook of Distance Education. Moore \& Anderson (Eds.). Mahwah, NJ: Lawrence Erlbaum Associates.

14. Heiman, M. \& Slomianko, J. (1986). Critical Thinking Skills. Washington, DC: National Education Association.

15. Horton, S. (2002). Web teaching guide. Retrieved 1/17/05 from http://www.webteachingguide.com/

16. Howard, G. (1999). We Can't Teach What We Don't Know. NY: Teachers College Press.

17. Jussim, L. (1986). Self-fulfilling prophecies: A Theoretical and Integrative review. Psychological Review, 93, 429-445.

18. Kirk, J. \& Orr, R. (2003). A primer on the effective use of threaded discussion forums. ED 472738.

19. Knowlton, D. (2001). Promoting Durable Knowledge Construction Through Online Discussion. ED 463724.

20. Mezirow, J. (1991). Transformative Dimensions of Adult Learning. San Francisco: Jossey-Bass.

21. Paley, V. (2000). White Teacher. Boston: Harvard Press. 
22. Pettit, R. \& Sugawara, A. (2001). Age, gender, socioeconomic status, race/ethnicity, temperament, and actual social and cognitive competence as factors contributing to pre-service teachers' perceptions of preschool children's social and cognitive competence. Journal of Early Childhood Teacher Education, 23(2). 125-136.

23. Sleeter, C. (2002). Diversity vs. white privilege. Rethinking Schools Online, 15(2). Winter 2000/01. Retrieved 1/25/05 from http://www.rethinkingschools.org/archive/15_02/Int152.shtml

24. Tiedt, P. \& Tiedt, I. (1999). Multicultural teaching: A Handbook of Activities information, and Resources. Needham Heights, MA: Allyn and Bacon.

25. Winiecki, D. (2003). Instructional discussions in online education: Practical and research-oriented perspectives. Handbook of Distance Education. Moore \& Anderson (Eds.). Mahwah, NJ: Lawrence Erlbaum Associates.

26. Wolfe, R. \& Falk-Ross, F. (2002). Impact of early clinical experiences on student attitudes about diversity. Journal of Early Childhood Teacher Education, 23 (2). 157-165.

27. Ziechner, K. (1992). Beyond inquiry-oriented teacher education: Rethinking the Practicum. ED 354223.

\section{NOTES}

